\title{
Prevalence of Giardiasis and Entamoeba Species in Two of the Six Governorates of Kuwait
}

\author{
Rania M. AlAyyar $\mathbb{D}^{1}{ }^{1}$ Abdullah A. AlAqeel, ${ }^{1}$ and Muna Sh. AlAwadhi ${ }^{2}$ \\ ${ }^{1}$ General Sciences Department, Institute of Nursing, Public Authority of Applied Education and Training (PAAET), \\ Shuwaikh, Kuwait \\ ${ }^{2}$ Laboratory Department, Alnafisi Dialysis Center, Ministry of Health, Shuwaikh, Kuwait
}

Correspondence should be addressed to Rania M. AlAyyar; r_alayyar@hotmail.com

Received 7 June 2021; Revised 17 February 2022; Accepted 19 February 2022; Published 4 March 2022

Academic Editor: Francisco Gonzalez Salazar

Copyright (c) 2022 Rania M. AlAyyar et al. This is an open access article distributed under the Creative Commons Attribution License, which permits unrestricted use, distribution, and reproduction in any medium, provided the original work is properly cited.

\begin{abstract}
Intestinal parasitic infections are a global concern owing to elevated rates of morbidity and mortality in many parts of the world. Increased rates of intestinal parasitic infections are observed in developing and low-income countries. In Kuwait, many expatriates and foreigners hail from endemic countries, thus increasing the rate and risk factor of infection. This retrospective study is aimed at assessing the prevalence of Giardia lamblia and Entamoeba sp. in stool samples handled by two of Kuwait's general hospitals during the period from January 2018 to July 2019: Mubarak Al Kabeer (serving Hawalli governorate population) and Aladan hospitals (serving Mubarak Al Kabeer governorate population) serving 27\% of total Kuwait population with Kuwaitis making up only $32 \%$. A total of 9,653 samples were tested for consistency and the availability of any parasitic particles using visual, direct wet mount, and concentration method. Statistical analysis was implemented using SPSS statistical program, at $p<0.05$. Of all the 9,653 tested stool samples, 74 were positive for G. lamblia or Entamoeba sp. This represented a mere $1 \%$ rate of infection and showed no significant correlation to the prevalence of intestinal parasite infections in Kuwait. On the other hand, comparing the rate of infection in different seasons revealed an increased rate of infection during spring compared to other seasons $(p=0.03)$. Findings revealed low rates of intestinal parasitic infection within the two governorates of Kuwait representing no statistical significance to the distribution of the investigated parasites in Kuwait. This may be attributed to improved living conditions and healthcare. Elevated infection rates in spring in relation to other seasons raised the importance of increasing public awareness during camping season for maintaining proper personal hygiene and waste management to contain and decrease the rate on infection.
\end{abstract}

\section{Introduction}

Intestinal parasitic infections (IPIs) are found to be one of the major public health problems worldwide [1-4]. An estimation by the World Health Organization (WHO) stated that over three billion people are infected with IPI worldwide, yet only 450 million are symptomatic [5]. Two of the most common IPIs are giardiasis and amoebiasis, where their mode of infection is highly dependent on the fecaloral rout $[6,7]$. This mode of infection may be acquired by direct or indirect transmission whether by person-toperson or indirectly through the use of contaminated food or objects $[8,9]$. Giardiasis and amoebiasis are two of the most prevailing IPIs, arising from ingesting the infective cyst stage of the responsible parasite, needless of an intermediate vector [10-12]. Giardiasis, referred to as lambliasis as well, is caused by the parasite Giardia lamblia (also known as G. duodenalis and G. intestinalis), while amoebiasis is caused by Entamoeba histolytica [12-15]. Postingestion of giardiasis infective stage, cysts excyst in the duodenum releasing trophozoite form that will adhere to the surface of the small intestine microvilli, thus obstructing absorption function of the small intestine, or may move freely within the lumen $[16,17]$. Though giardiasis is mostly asymptomatic, symptoms may prevail within 3 to 15 days postingestion, manifesting as a variety of symptoms, ranging from mild 
nutrient malabsorption and intestinal uneasiness up to a more acute stages with bloody, fatty stool, explosive diarrhea, vomiting, and anorexia [16-19]. With diarrhea being the second leading cause of morbidity and mortality due to infectious disease, proper diagnosis and treatment are essential [20]. In amoebiasis, the ingested infective cyst stage excysts in the small intestine as well but colonizes and invades the large intestine mucosal layer. Infection may develop further into an extraintestinal infection migrating to different parts of the host body including liver, brain, and lungs [21-23]. It is essential to note here that there are four morphologically identical Entamoeba species indistinguishable under the microscope, E. histolytica, E. dispar, E. bangladishi, and E. moshkovskii, with $E$. histolytica being the only causative agent of amoebiasis, while the latter three are considered commensal, noninfective species. Although recent studies have implicated the role of $E$. dispar and E. moshkovskii as potential pathogens to humans, yet a more precise diagnosis approach is essential in identifying the Entamoeba sp. under investigation to prevent unnecessary treatment [22-24]. According to the WHO guidelines, polymer chain reaction (PCR) is the approved method for identifying and differentiating the Entamoeba sp. [24]. Similar to giardiasis, almost $90 \%$ of amoebiasis infections are asymptomatic, while if symptomatic, infection may manifest in a range of symptoms from mild diarrhea to abdominal cramps, bloody, watery diarrhea, dysentery, and abscess formation [21, 22]. Both IPIs are found responsible for increasing morbidity in many parts of the world, especially in developing and low-income countries $[5,25,26]$. Amoebiasis is estimated to infect 480 million people globally, with elevated annual deaths ranging between 40 and over 100 thousand people, and nonetheless, giardiasis, while not life threatening, has an annual infection estimated at 280 million people worldwide [27-30]. According to the Global Burden of Disease Study 2010, the median global burden of giardiasis was estimated at 0.17 million, while the burden of amoebiasis was 0.5 million disabilityadjusted life years $[6,31]$. Some of the major risk factors involved in facilitating the spread of IPI are improper personal hygiene, feeble sanitary conditions, and deprived access to clean water supply [26, 32-34].

Kuwait is a developed country in the Middle East, positioned at the northeastern corner of the Arabian Gulf (Figure 1) [35, 36]. Kuwait attracts various employment seekers from all over the world, many of which hail from low-income or developing countries where elevated rates of IPI are recorded [2, 33, 37]. House staff, food handlers, healthcare personal, and many other occupations are considered high-risk factors for IPI transmission due to occupational nature, thus increasing infection exposure rates either by direct or indirect contact. According to the statistical reports of Kuwait's Public Authority of Civil Information (PACI) in 2019, total Kuwait population was stated to be $4,776,407$, with Kuwaitis making up only $30 \%$ [38].

Several studies indicated the role of human mobility in the transmission of infectious diseases [39]. Shedding a light on the degree of IPI distribution in Kuwait could help in containing the infection. Hence, this study is aimed at estimating the prevalence of giardiasis and amoebiasis in two of Kuwait's governorates.

\section{Materials and Methods}

2.1. Study Site and Population. A retrospective study conducted on the archival records in two of Kuwait's public hospitals: Mubarak Al Kabeer hospital, which serves 16 cities comprising Hawalli governorate, and Aladan hospital, serving 13 cities comprising Mubarak Al Kabeer governorate (Figure 1). Both hospitals serve a total of 1,275,407 people, in which only $32 \%$ are of Kuwaiti nationality [38].

Hospitals' archival departments were the source of our data, retaining the confidentiality of all patient personal information and records. Ethical approvals and documentations were obtained from Kuwait Ministry of Health prior to data collection. Findings of all stool samples received by the microbiology laboratory department in both hospitals during the period from January 2018 to July 2019 were recorded. A total of 9,653 stool samples were handled by the microbiology laboratory department in both hospitals, 6,264 in Aladan hospital and 3,299 samples in Mubarak Al Kabeer hospital.

2.2. Sample Collection and Processing. Sample collection and processing in Kuwait hospitals and laboratories fall under the guidelines set by the Kuwait Ministry of Health in accordance with the WHO guidelines [41]. Stool samples are collected in a clean, wide-mouthed, plastic container with a tightly sealed cover. Upon receiving the samples, laboratory technicians check and record the sample consistency and presence of any mucus, blood, or parasitic materials and apply further preparation for microscopic examination using direct wet mount. Upon request or if sample seems soft or watery, concentration method is performed, using Fecal Parasite Concentrator (FPC) kit by Evergreen Scientific company. For wet mount method, a drop of normal saline is placed on one-half of a glass slide, and Lugol's iodine solution on the other half. A tiny portion of the stool sample is then applied to each solution and mixed well in preparation for microscopic examination. Concentration method, performed when required, follows similar guidelines applied in wet mount microscopic examination, yet the main solution used is normal saline, followed by another staining solution specific for the suspected form.

2.3. Statistical Analysis. Chi-square test was implemented to determine any correlation significance with the aid of SPSS version 25 (IBM, Franklin D Roosevelt, Manhattan, NY), and the $p$ value considered significant at values $<0.05$.

\section{Results}

A total of 9,563 stool samples were processed by the microbiology laboratory department of both Aladan and Mubarak Al Kabeer hospitals. Recorded results for each sample were collected and classified according to the prevalence of $G$. lamblia and E. histolytica/dispar in each hospital and were further categorized according to season during which samples were collected in the period from January 2018 until July 2019.

From the 6,264 samples processed by Aladan hospital, 51 $(0.81 \%)$ came positive, 43 with $G$. lamblia and 8 with 


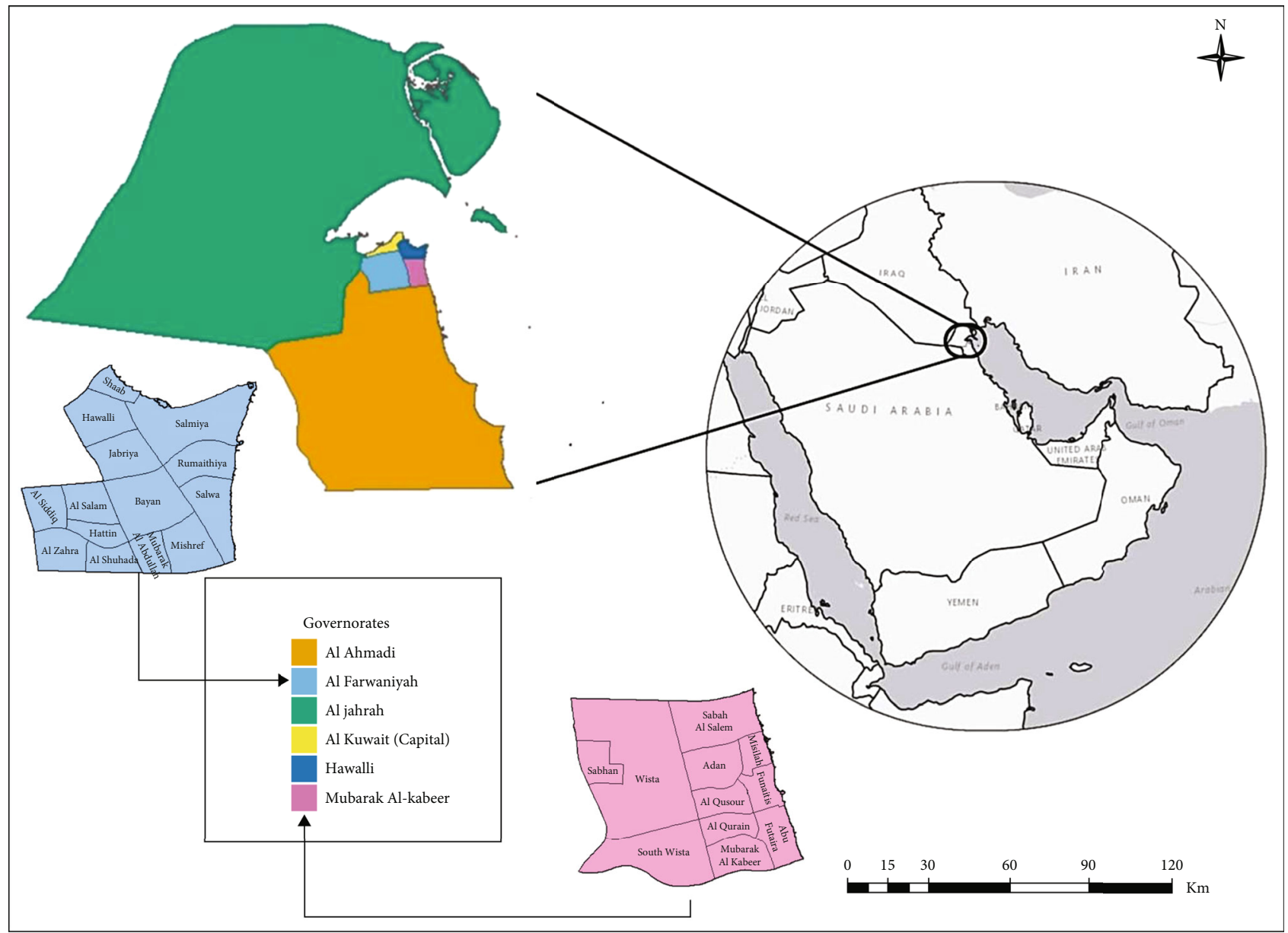

Figure 1: Map of Kuwait showing the six governorates and the cities of Hawalli and Mubarak Al Kabeer governorates [36, 40].

Entamoeba sp. On the other hand, of the 3,299 samples processed by Mubarak Al Kabeer hospital, only 23 (0.70\%) were positive for Entamoeba sp., lacking the presence of $G$. lamblia. Overall, a total of 74 positive samples were detected, 31 Entamoeba sp. (8 in Aladan and 23 in Mubarak Al Kabeer hospital) and 43 G. lamblia only in Aladan hospital representing only $0.77 \%$ of the 9,563 samples tested in both hospitals (Table 1).

Data collected was also classified according to season (Table 2). Highest rates of infection were observed in spring, with 35 positive samples, 16 G. lamblia detected only in Aladan hospital and 19 Entamoeba sp., 6 in Aladan and 13 in Mubarak Al Kabeer hospital, making up 1.19\% of the total samples received during the spring season. These findings represented $47 \%$ of total infected samples in our study. Significant correlation was observed between the rate of infection and different seasons with the $p$ value estimated at 0.033 .

\section{Discussion}

It is well established that IPI is a worldwide burden, owing to increasing morbidity and mortality [42-45]. According to the WHO, over two billion people are currently harboring IPI throughout the world [46]. Poor deprived commu- nities with low socioeconomical and educational status, where improper waste and sewage management, poor hygienic habits, limited access to clean water supply, and ignorance of appropriate personal practices are more prone to IPI dissemination [42, 45, 47-51]. In Kuwait and other Arabian Gulf countries, many expatriates and residents originate from these parts of the world thus implementing a great risk factor to the spread of intestinal parasites due to occupational nature $[1,5,51]$. Previous studies within Arabian Gulf countries estimated the prevalence of IPI to range between 2.3 and $47 \%, 7.7 \%$ in the UAE, $10.2 \%$ in Qatar, and $2.3-47 \%$ throughout the KSA $[47,51]$. Our study focuses on the prevalence of giardiasis and amoebiasis in only two of Kuwait's highly populated governorates, Hawalli and Mubarak Al Kabeer. Of the 9,563 stool samples tested, only 74 were recognized with parasitic findings. This represented $0.77 \%$ infection rate showing insignificant correlation to the spread of IPI in Kuwait, driving against our estimated hypothesis. This may be attributed to the improved lifestyle and living condition and proper healthcare in Kuwait or the fact that most samples belong citizens due to recently enforced medical fees refraining many foreigners from pursuing proper testing. The latter cannot be confirmed currently due to unavailability of personal data, nationality, on 
TABle 1: Prevalence of parasitic infection in Hawalli governorate (Mubarak Al Kabeer hospital) and in Mubarak Al Kabeer governorate (Aladan hospital).

\begin{tabular}{lccccc}
\hline Hospital & Total samples & Infected & $(\%)$ & G. lamblia & Entamoeba sp. \\
\hline Aladan & 6,264 & 51 & $0.81 \%$ & 43 & 8 \\
Mubarak Al Kabeer & 3,299 & 23 & $0.70 \%$ & Null & 23 \\
Total & 9,563 & 74 & $0.77 \%$ & 43 & 31 \\
\hline
\end{tabular}

Table 2: Prevalence of G. lamblia and Entamoeba sp. in different seasons (2018-2019).

\begin{tabular}{|c|c|c|c|c|c|c|c|c|}
\hline \multirow{2}{*}{ Parasite } & \multicolumn{2}{|c|}{ Winter } & \multicolumn{2}{|c|}{ Spring } & \multicolumn{2}{|c|}{ Summer } & \multicolumn{2}{|c|}{ Autumn } \\
\hline & No. & $p(\%)$ & No. & $p(\%)$ & No. & $p(\%)$ & No. & $p(\%)$ \\
\hline G. lamblia & 12 & $0.48 \%$ & 16 & $0.54 \%$ & 13 & $0.35 \%$ & 2 & $0.43 \%$ \\
\hline Entamoeba sp. & 4 & $0.16 \%$ & 19 & $0.65 \%$ & 10 & $0.27 \%$ & 0 & $0.00 \%$ \\
\hline Total positive (\%) & 16 & $0.64 \%$ & 35 & $1.19 \%$ & 23 & $0.63 \%$ & 2 & $0.43 \%$ \\
\hline Total samples & \multicolumn{2}{|c|}{2487} & \multicolumn{2}{|c|}{2944} & \multicolumn{2}{|c|}{3663} & \multicolumn{2}{|c|}{469} \\
\hline
\end{tabular}

samples investigated in this study; thus, a more targeted approach is recommended emphasizing participants' details on a personal level.

Differentiating morphologically identical Entamoeba sp. was not established since the required method (i.e., PCR) is not routinely performed in the Kuwait Ministry of Health. Amoebic findings were thus generalized and expressed as Entamoeba sp. (E. histolytica/E. dispar/E. bangladeshi/E. moshkovskii complex).

Data was further analyzed according to season, revealing significant correlation, at $p=0.033$, to spring over other seasons which was consistent with previous reports [47]. Most common spring activity in Kuwait is desert camping, where limited access to running water and improper waste management are a main concern. Thus, public awareness and education on proper hygienic performances and waste management during camping season are essential to withhold against the spread of parasites.

\section{Conclusion}

Our finding revealed a low rate of giardiasis and amoebiasis in two of Kuwait's six governorates, representing insignificant risk factor for IPI. This may be attributed to enhanced living conditions, accessible healthcare throughout Kuwait, and the role of public awareness in limiting the spread of transmitted diseases on a global scale.

During camping season, infection rates were assessed highest, emphasizing the importance of public education and awareness on proper personal hygienic approaches and waste management to ensure withholding the spread of parasites.

\section{Data Availability}

Data used to support this study are fully available, and detailed data are available from the corresponding author upon request.

\section{Conflicts of Interest}

The authors declare that there is no conflict of interest regarding the publication of this article.

\section{Acknowledgments}

The authors would like to acknowledge the role of Kuwait's Ministry of Health in facilitating hospital communication and data collection.

\section{References}

[1] F. Kheirandish, M. J. Tarahi, and B. Ezatpour, "Prevalence of intestinal parasites among food handlers in Western Iran," Revista do Instituto de Medicina Tropical de São Paulo, vol. 56, no. 2, pp. 111-114, 2014.

[2] A. S. Jaran, "Prevalence and seasonal variation of human intestinal parasites in patients attending hospital with abdominal symptoms in northern Jordan," Eastern Mediterranean Health Journal, vol. 22, no. 10, pp. 756-760, 2017.

[3] M. J. Abbaszadeh Afshar, M. Barkhori Mehni, M. Rezaeian et al., "Prevalence and associated risk factors of human intestinal parasitic infections: a population-based study in the southeast of Kerman province, southeastern Iran," BMC Infectious Diseases, vol. 20, no. 1, p. 12, 2020.

[4] P. Suntaravitun and A. Dokmaikaw, "Prevalence of intestinal parasites and associated risk factors for infection among rural communities of Chachoengsao Province,Thailand," Korean Journal of Parasitology, vol. 56, no. 1, pp. 33-39, 2018.

[5] M. A. Abu-Madi, J. M. Behnke, S. Boughattas, A. Al-Thani, and S. H. Doiphode, "A decade of intestinal protozoan epidemiology among settled immigrants in Qatar," BMC Infectious Diseases, vol. 16, no. 1, pp. 1-9, 2016.

[6] A. Al-Jawabreh, S. Ereqat, K. Dumaidi, H. Al-Jawabreh, Z. Abdeen, and A. Nasereddin, "Prevalence of selected intestinal protozoan infections in marginalized rural communities in Palestine," BMC Public Health, vol. 19, no. 1, pp. 1-11, 2019.

[7] M. Osman, D. El Safadi, A. Cian et al., "Prevalence and risk factors for intestinal protozoan infections with Cryptosporidium, Giardia, Blastocystis and Dientamoeba among 
schoolchildren in Tripoli, Lebanon," PLoS Neglected Tropical Diseases, vol. 10, no. 3, article e0004496, 2016.

[8] M. Mama and G. Alemu, "Prevalence and factors associated with intestinal parasitic infections among food handlers of Southern Ethiopia: cross sectional study," BMC Public Health, vol. 16 , no. 1 , pp. $1-7,2016$.

[9] L. Quihui-Cota, G. G. Morales-Figueroa, A. Javalera-Duarte, J. A. Ponce-Martínez, E. Valbuena-Gregorio, and M. A. López-Mata, "Prevalence and associated risk factors for Giardia and Cryptosporidium infections among children of northwest Mexico: a cross-sectional study," BMC Public Health, vol. 17, no. 1, p. 852, 2017.

[10] M. Shahnazi, M. Sadeghi, M. Saraei, M. Alipour, and E. Hajialilo, "Prevalence of parasitic intestinal infections among food handlers in Qazvin,Iran," Turkiye Parazitolojii Dergisi, vol. 43, no. 1, pp. 16-20, 2019.

[11] A. Higuera, X. Villamizar, G. Herrera et al., "Molecular detection and genotyping of intestinal protozoa from different biogeographical regions of Colombia," Peer J., vol. 8, article e8554, 2020.

[12] J. C. Carrero, M. Reyes-López, J. Serrano-Luna et al., "Intestinal amoebiasis: 160 years of its first detection and still remains as a health problem in developing countries," International Journal of Medical Microbiology, vol. 310, no. 1, article 151358, 2020.

[13] M. Y. Fink and S. M. Singer, "The intersection of immune responses, microbiota, and pathogenesis in giardiasis," Trends in Parasitology, vol. 33, no. 11, pp. 901-913, 2017.

[14] A. K. C. Leung, A. A. M. Leung, A. H. C. Wong, C. M. Sergi, and J. K. M. Kam, "Giardiasis: an overview," Recent Patents on Inflammation \& Allergy Drug Discovery, vol. 13, no. 2, pp. 134-143, 2019.

[15] H. M. G. Zulfiqar and S. Horrall, "Amebiasis. In: [Internet] S, editor. Stat Pearl Amebiasis. Treasure Island (FL)," Stat Pearls Publishing, USA, 2020.

[16] M. S. Wolfe, "Giardiasis," Clinical Microbiology Reviews, vol. 5, no. 1, pp. 93-100, 1992.

[17] S. Solaymani-Mohammadi, J. M. Genkinger, C. A. Loffredo, and S. M. Singer, "A meta-analysis of the effectiveness of albendazole compared with metronidazole as treatments for infections with Giardia duodenalis," PLoS Neglected Tropical Diseases, vol. 4, no. 5, article e682, 2010.

[18] J. C. Auriostigue-Bautista, E. Hernández-Vázquez, D. González-Calderón et al., "Discovery of benzopyrrolizidines as promising antigiardiasic agents," Frontiers in Cellular and Infection Microbiology, vol. 11, article 828100, 2021.

[19] P. A. Flanagan, "Giardia-diagnosis, clinical course and epidemiology," Epidemiology and Infection, vol. 109, no. 1, pp. 122, 1992.

[20] N. Roshidi, N. H. Mohd Hassan, A. Abdul Hadi, and N. Arifin, "Current state of infection and prevalence of giardiasis in Malaysia: a review of 20 years of research," Peer J., vol. 9, article e12483, 2021.

[21] C. Ximénez, R. Cerritos, L. Rojas et al., "Human amebiasis: breaking the paradigm?," International Journal of Environmental Research and Public Health, vol. 7, no. 3, pp. 11051120, 2010.

[22] M. Kantor, A. Abrantes, A. Estevez, A. Schiller, J. Torrent, J. Gascon et al., "Entamoeba histolytica: updates in clinical manifestation, pathogenesis, and vaccine development," Canadian Journal of Gastroenterology \& Hepatology, vol. 2018, article 4601420, 2018.
[23] M. H. Flaih, R. M. Khazaal, M. K. Kadhim, K. R. Hussein, and F. A. B. Alhamadani, "The epidemiology of amoebiasis in ThiQar Province, Iraq (2015-2020): differentiation of Entamoeba histolytica and Entamoeba dispar using nested and real-time polymerase chain reaction," Epidemiol Health., vol. 43, article e2021034, 2021.

[24] R. Abozahra, M. Mokhles, and K. Baraka, "Prevalence and molecular differentiation of Entamoeba histolytica, Entamoeba dispar, Entamoeba moshkovskii, and Entamoeba hartmanni in Egypt," Acta Parasitologica, vol. 65, no. 4, pp. 929-935, 2020.

[25] B. Sitotaw and W. Shiferaw, "Prevalence of intestinal parasitic infections and associated risk factors among the first-cycle primary schoolchildren in Sasiga District,Southwest Ethiopia," Journal of Parasitology Research, vol. 2020, Article ID 8681247, 13 pages, 2020.

[26] C. V. Barbosa, M. M. Barreto, R. J. Andrade et al., "Intestinal parasite infections in a rural community of Rio de Janeiro (Brazil): prevalence and genetic diversity of Blastocystis subtypes," PLoS One, vol. 13, no. 3, article e0193860, 2018.

[27] A. F. Espinosa Aranzales, K. Radon, G. Froeschl, Á. Pinzón Rondón, and M. Delius, "Prevalence and risk factors for intestinal parasitic infections in pregnant women residing in three districts of Bogotá, Colombia," BMC Public Health, vol. 18, no. 1, p. 1071, 2018.

[28] P. Zajaczkowski, S. Mazumdar, S. Conaty, J. T. Ellis, and S. M. Fletcher-Lartey, "Epidemiology and associated risk factors of giardiasis in a peri-urban setting in New South Wales Australia," Epidemiology and Infection, vol. 147, 2018.

[29] A. A. Sayyari, F. Imanzadeh, S. A. Bagheri Yazdi, H. Karami, and M. Yaghoobi, "Prevalence of intestinal parasitic infections in the Islamic Republic of Iran," Eastern Mediterranean Health Journal, vol. 11, no. 3, pp. 377-383, 2005.

[30] S. Pearls, 2020.

[31] V. Greigert, A. Abou-Bacar, J. Brunet et al., "Human intestinal parasites in Mahajanga, Madagascar: the kingdom of the protozoa," PLoS One, vol. 13, no. 10, article e0204576, 2018.

[32] K. Saurabh, V. L. Nag, D. Khera, and P. Elhence, "Giardiasis mimicking celiac disease in a patient of common variable immunodeficiency," Trop Parasitol., vol. 7, no. 2, pp. 125127, 2017.

[33] B. Nkrumah and S. B. Nguah, "Giardia lamblia: a major parasitic cause of childhood diarrhoea in patients attending a district hospital in Ghana," Parasites \& Vectors, vol. 4, pp. 1-7, 2011.

[34] M. V. Periago, R. García, O. G. Astudillo, M. Cabrera, and M. C. Abril, "Prevalence of intestinal parasites and the absence of soil-transmitted helminths in Añatuya, Santiago del Estero, Argentina," Parasites \& Vectors, vol. 11, no. 1, p. 638, 2018.

[35] Y. Yuan, B. Alahmad, C. M. Kang et al., "Dust events and indoor air quality in residential homes in Kuwait," International Journal of Environmental Research and Public Health, vol. 17, no. 7, article 2433, 2020.

[36] B. Alahmad, L. P. Tomasso, A. Al-Hemoud, P. James, and P. Koutrakis, "Spatial distribution of land surface temperatures in Kuwait: urban heat and cool islands," International Journal of Environmental Research and Public Health, vol. 17, no. 9, 2020.

[37] X. Villamizar, A. Higuera, G. Herrera et al., "Molecular and descriptive epidemiology of intestinal protozoan parasites of children and their pets in Cauca, Colombia: a cross-sectional study," BMC Infectious Diseases, vol. 19, no. 1, pp. 1-11, 2019. 
[38] PACI TPAfCI, "PACI statistical reports," stat PACIgovkw, 2019, http://stat.paci.gov.kw/englishreports/.

[39] F. Castelli and G. Sulis, "Migration and infectious diseases," Clinical Microbiology and Infection, vol. 23, no. 5, pp. 283289, 2017.

[40] K. Municipality, 2018, //http://www.baladia.gov.kw/.

[41] WorldHealthOrganization, "Basic laboratory methods in medical parasitology," in World Health Organization, Geneva, 1991.

[42] C. P. Faria, G. M. Zanini, G. S. Dias et al., "Geospatial distribution of intestinal parasitic infections in Rio de Janeiro (Brazil) and its association with social determinants," PLoS Neglected Tropical Diseases, vol. 11, no. 3, article e0005445, 2017.

[43] A. Jejaw, A. Zeynudin, E. Zemene, and T. Belay, "Status of intestinal parasitic infections among residents of Jimma Town,Ethiopia," BMC Research Notes, vol. 7, article 502, 2014.

[44] I. Sangaré, S. Bamba, M. Cissé et al., "Prevalence of intestinal opportunistic parasites infections in the university hospital of Bobo-Dioulasso,Burkina Faso," Infectious Diseases of Poverty, vol. 4, pp. 1-6, 2015.

[45] S. Tandukar, S. Ansari, N. Adhikari et al., "Intestinal parasitosis in school children of Lalitpur district of Nepal," BMC Research Notes, vol. 6, pp. 1-6, 2013.

[46] A. Gelaw, B. Anagaw, B. Nigussie et al., "Prevalence of intestinal parasitic infections and risk factors among schoolchildren at the University of Gondar Community School, Northwest Ethiopia: a cross-sectional study," BMC Public Health, vol. 13, pp. 1-7, 2013.

[47] O. S. O. Amer, E. S. Al-Malki, M. I. Waly, A. AlAgeel, and M. Y. Lubbad, "Prevalence of intestinal parasitic infections among patients of King Fahd Medical City in Riyadh Region, Saudi Arabia: a 5-year retrospective study," Journal of Parasitology Research, vol. 2018, Article ID 8076274, 8 pages, 2018.

[48] İ. Arıkan, A. Gülcan, and S. E. Dibeklıŏlu, "Investigation of factors affecting frequency of intestinal parasites in primary school students in an urban region in Turkey," Central European Journal of Public Health, vol. 24, no. 3, pp. 193-198, 2016.

[49] K. O. Duedu, Y. A. Karikari, S. K. Attah, and P. F. Ayeh-Kumi, "Prevalence of intestinal parasites among patients of a Ghanaian psychiatry hospital," BMC Research Notes, vol. 8, pp. 1-5, 2015.

[50] L. G. Curval, A. D. O. Franca, H. J. Fernandes et al., "Prevalence of intestinal parasites among inmates in Midwest Brazil," PLoS One, vol. 12, no. 9, article e0182248, 2017.

[51] A. I. A. Dafalla, S. A. S. O. Almuhairi, M. H. J. AlHosani et al., "Intestinal parasitic infections among expatriate workers in various occupations in Sharjah, United Arab Emirates," Revista do Instituto de Medicina Tropical de São Paulo, vol. 59, article e82, 2017. 